\title{
LETTERS
}

\section{Impact of COVID-19 on pediatric clinical research in France}

As stated by Cheng and colleagues, ${ }^{1}$ temptations to use unproven medications and strategies instead of relying on scientific evidence are high when facing the frightening coronavirus disease 2019 (COVID19) pandemic. Most medical and scientific communities have reacted promptly to better fight the disease. This is a particular challenge in pediatric clinical research.

PEDSTART (www.pedstart.org/en) is the national network of French pediatric clinical research centres. A task force has been created to gather all national research initiatives and anticipate the consequences of COVID-19 on pediatric clinical research. At present, we have identified no fewer than 15 projects at different stages of maturity involving pediatric patients. Overlap between studies is frequent, and multiplicity of trials may jeopardize a relevant approach. Each pediatric clinical investigation centre had to reorganize itself rapidly, while meeting the triple requirement of limiting travel and contact with patients, protecting hospital staff from infection, and reducing the activity of the hospital to ensure there are enough staff and beds for patients with COVID-19. Negative and positive effects have been observed. Although COVID-19 has strengthened team cohesion and involvement, we have to face a decrease in activity of pediatric clinical research. Supply management of investigational medicinal products and good clinical practices will be challenged by unprecedented adaptations of research infrastructure.

This period may be a chance to merge projects and to join forces to deal with the resumption of "usual" activity, which will be a challenging task in itself. We encourage and support the merging of riskmitigation activities at an international level to better anticipate and respond to the impact of COVID-19 on ongoing and future pediatric clinical research.

\section{Florence Flamein MD PhD}

Pediatrician, French Clinical Research Infrastructure Network (F-CRIN) PEDSTART, Centre Hospitalier Universitaire de Lille, University of Lille, Lille, France

\section{Frederic Gottrand MD PhD}

Professor of pediatrics, French Clinical

Research Infrastructure Network (F-CRIN) - PEDSTART, Centre Hospitalier Universitaire de Lille, University of Lille, Lille, France

\section{Maya Laxmi Patel MSc}

Project manager, French Clinical Research Infrastructure Network (F-CRIN) PEDSTART, University of Tours, Institut National de la Santé et de la Recherche Médicale, Tours, France

\section{Régis Hankard MD PhD}

Professor of pediatrics, French Clinical Research Infrastructure Network (F-CRIN) - PEDSTART, University of Tours, Institut National de la Santé et de la Recherche Médicale, Tours, France

Cite as: CMAJ 2020 May 25;192:E589. doi: $10.1503 / \mathrm{cmaj} .75416$

\section{Reference}

1. Cheng MP, Lee TC, Tan DHS, et al. Generating randomized trial evidence to optimize treatment in the COVID-19 pandemic. CMAJ 2020;192: E405-7.

Competing interests: None declared. 